\title{
Immersing students into water research: utilizing over a decade well field data.
}

K Solomon A Isiorho,

Professor Emeritus of Geology, Biology Department, Indiana University-Purdue University Ft. Wayne (IPFW),

Ft Wayne, IN 46805 
Chinese Proverb If you want

- 1 year of prosperity, grow grain

- 10 years of prosperity, grow trees, and

- 100 years of prosperity, grow people

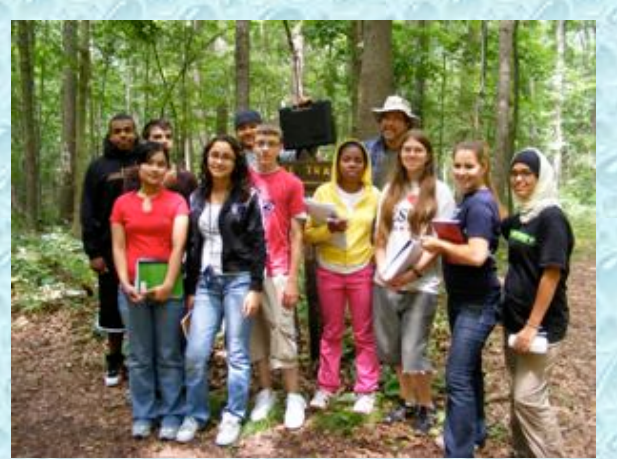



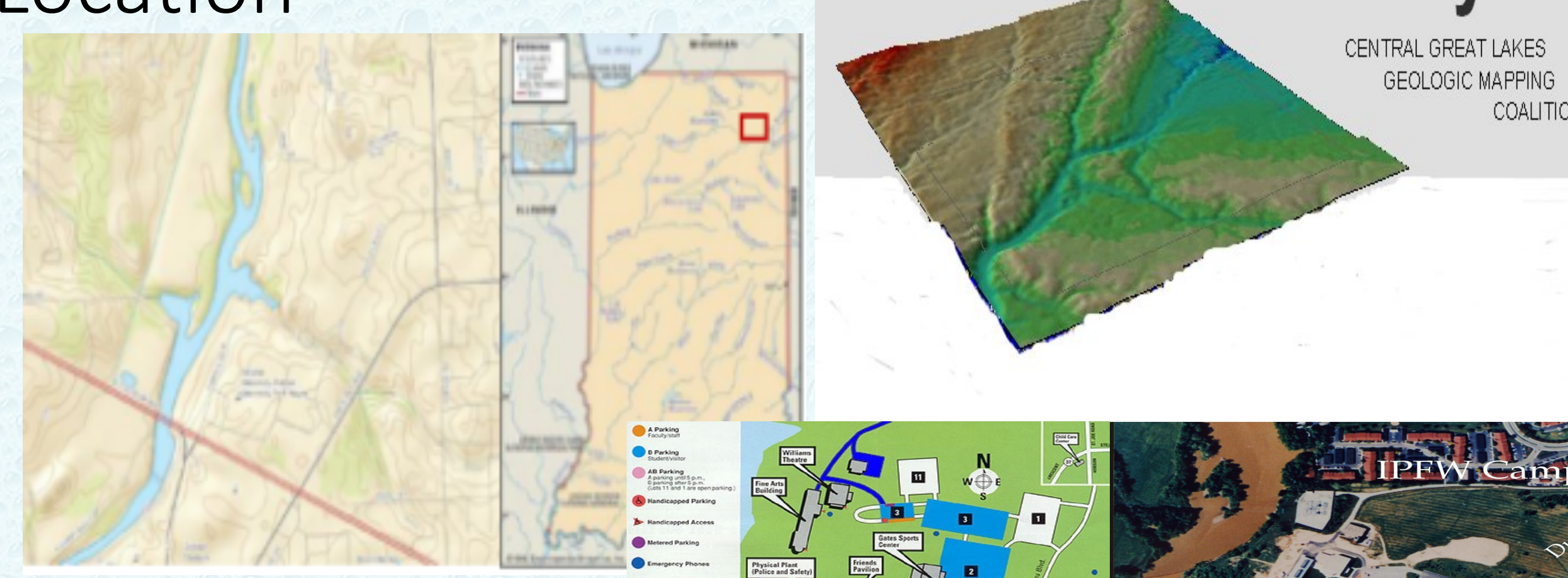

GEOLOGIC MAPPING

COALITION

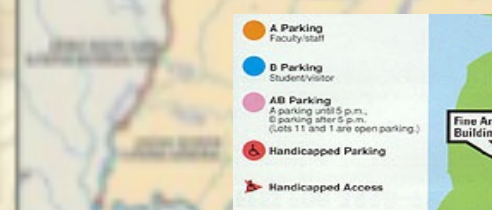

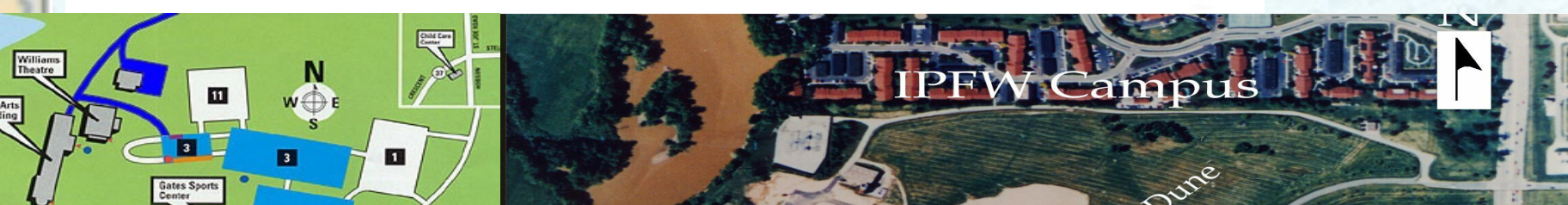

$=$

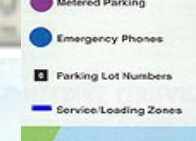

(5)

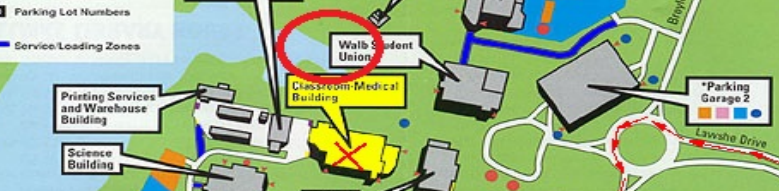

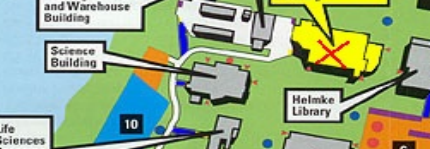

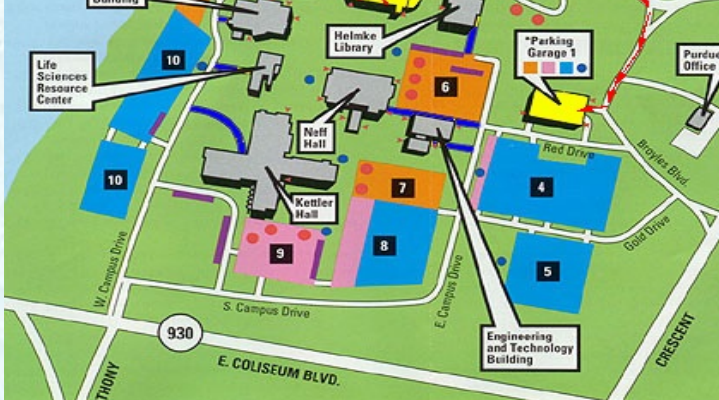




\section{Well field}

- How many wells?
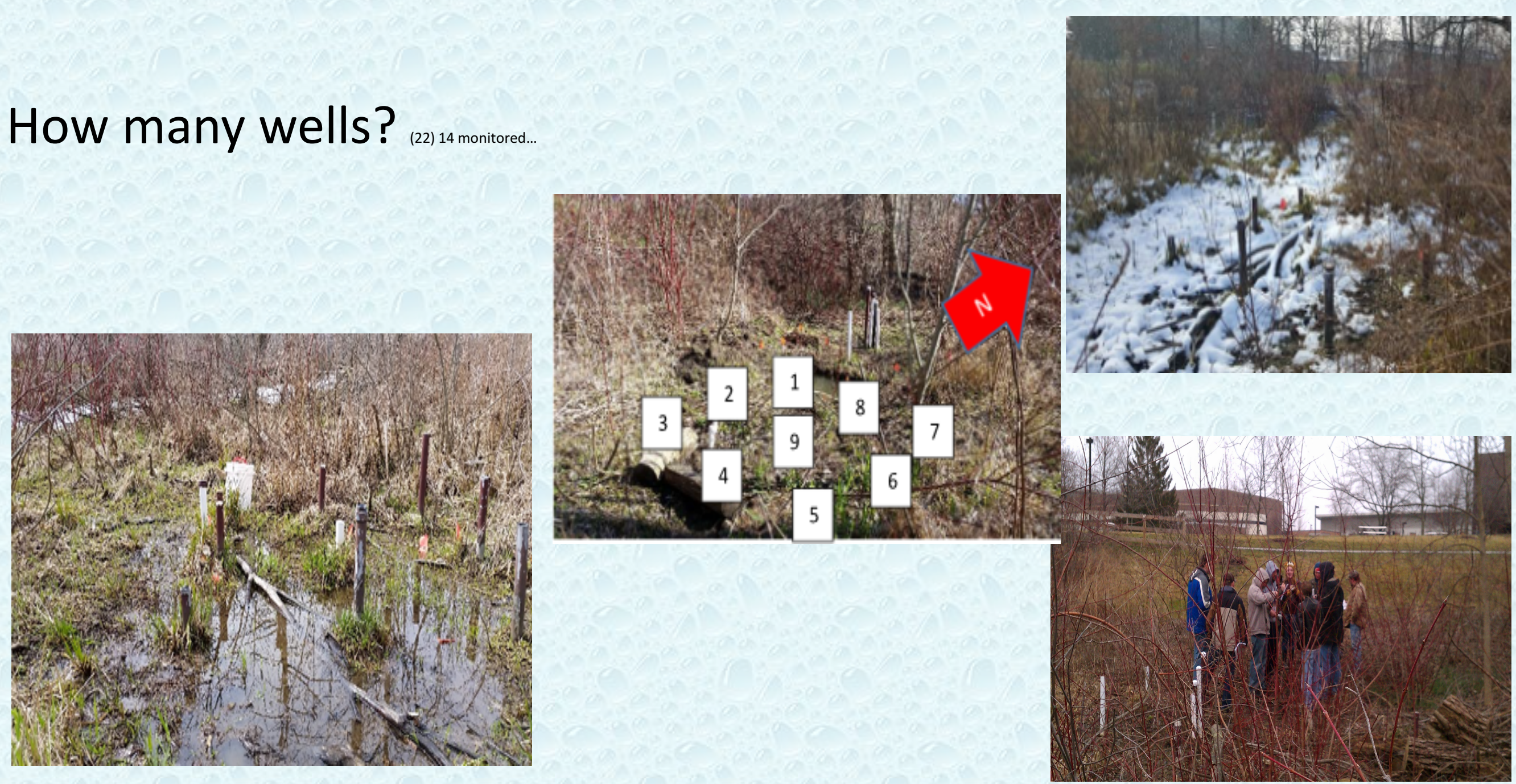


\section{What's being Used for}

- Introductory geology lab,

- Wetland studies

- Environmental Conservation to

- Advanced level hydrogeology courses.

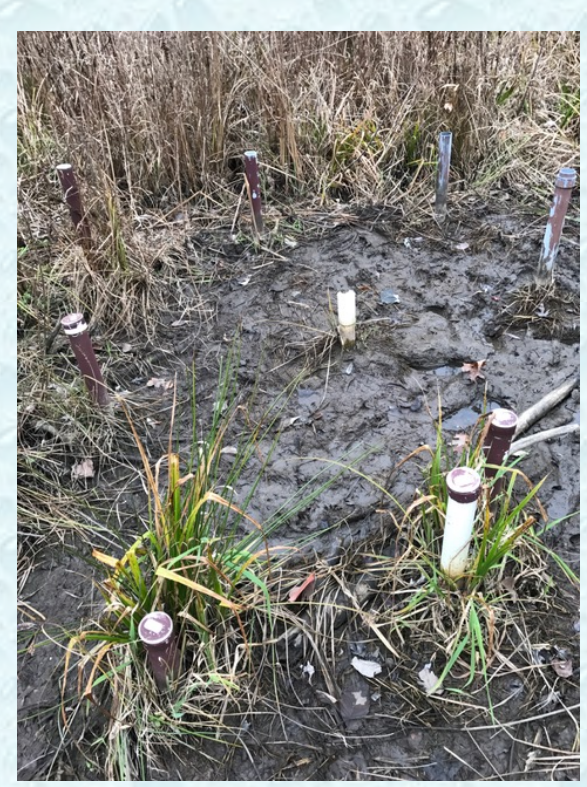

- More than ten wells, are used to demonstrate some surface water ground water interactions and have been used to show anthropogenic affect on groundwater quality

- Several field observations and measurements

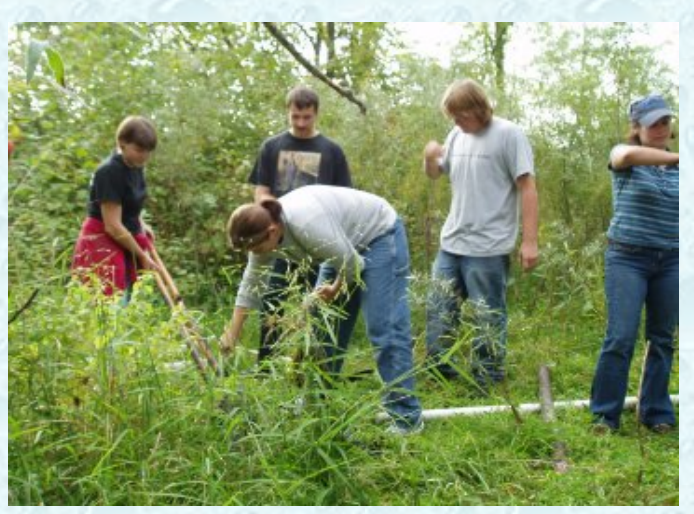


- "Drilling" wells

- Sediment samples

- Sieve analysis

- Water samples

- Analysis of data

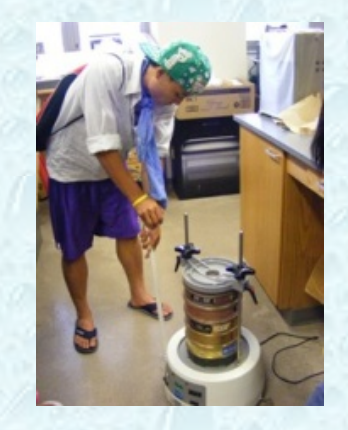

- Report and presentations to peers

\section{Methods \& Materials}
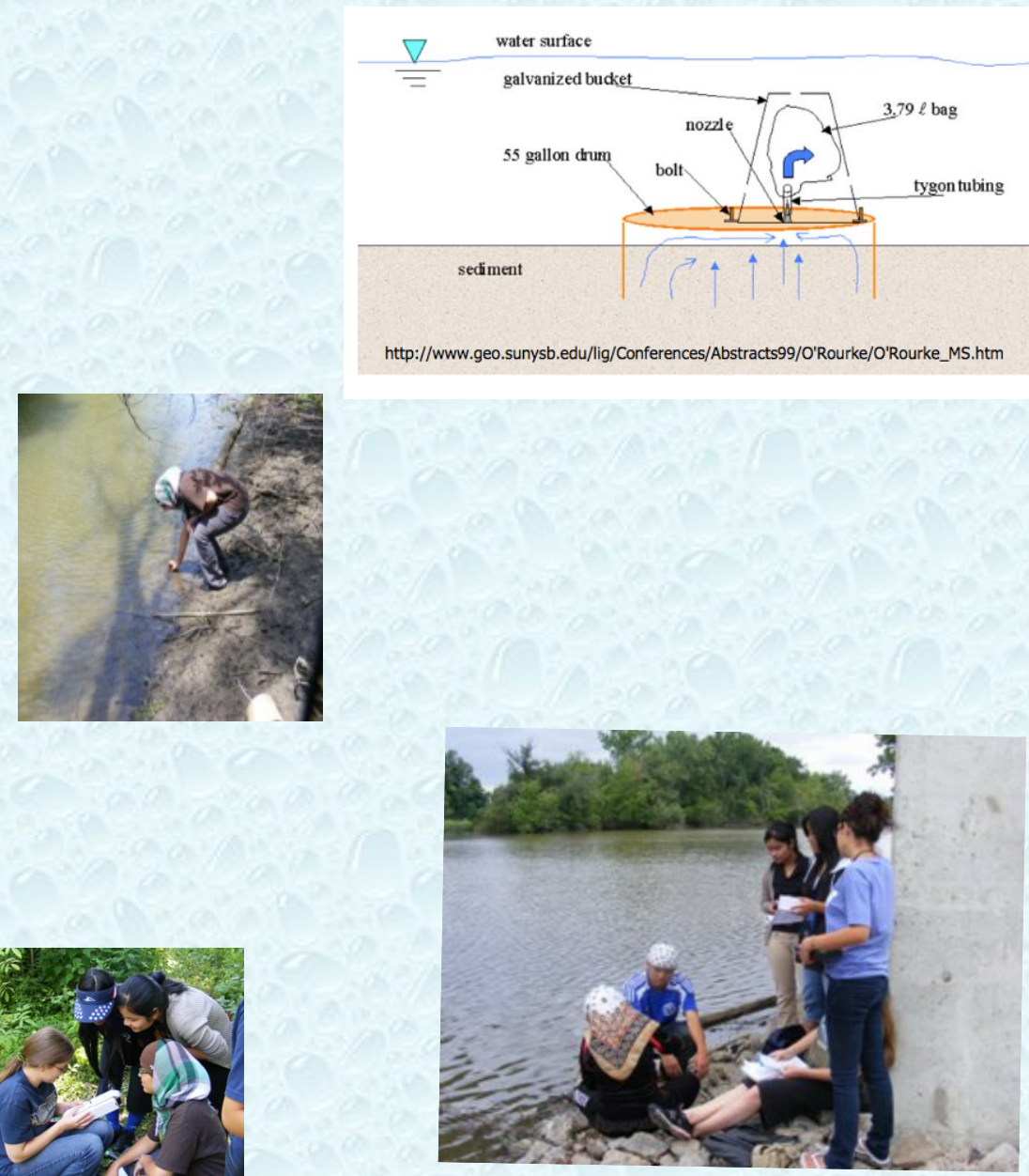
First couple years
- depth to groundwater, groundwater flow direction to temperature and nutrients (nitrates and phosphates) ... measurements made by students in the various classes.

- 2005
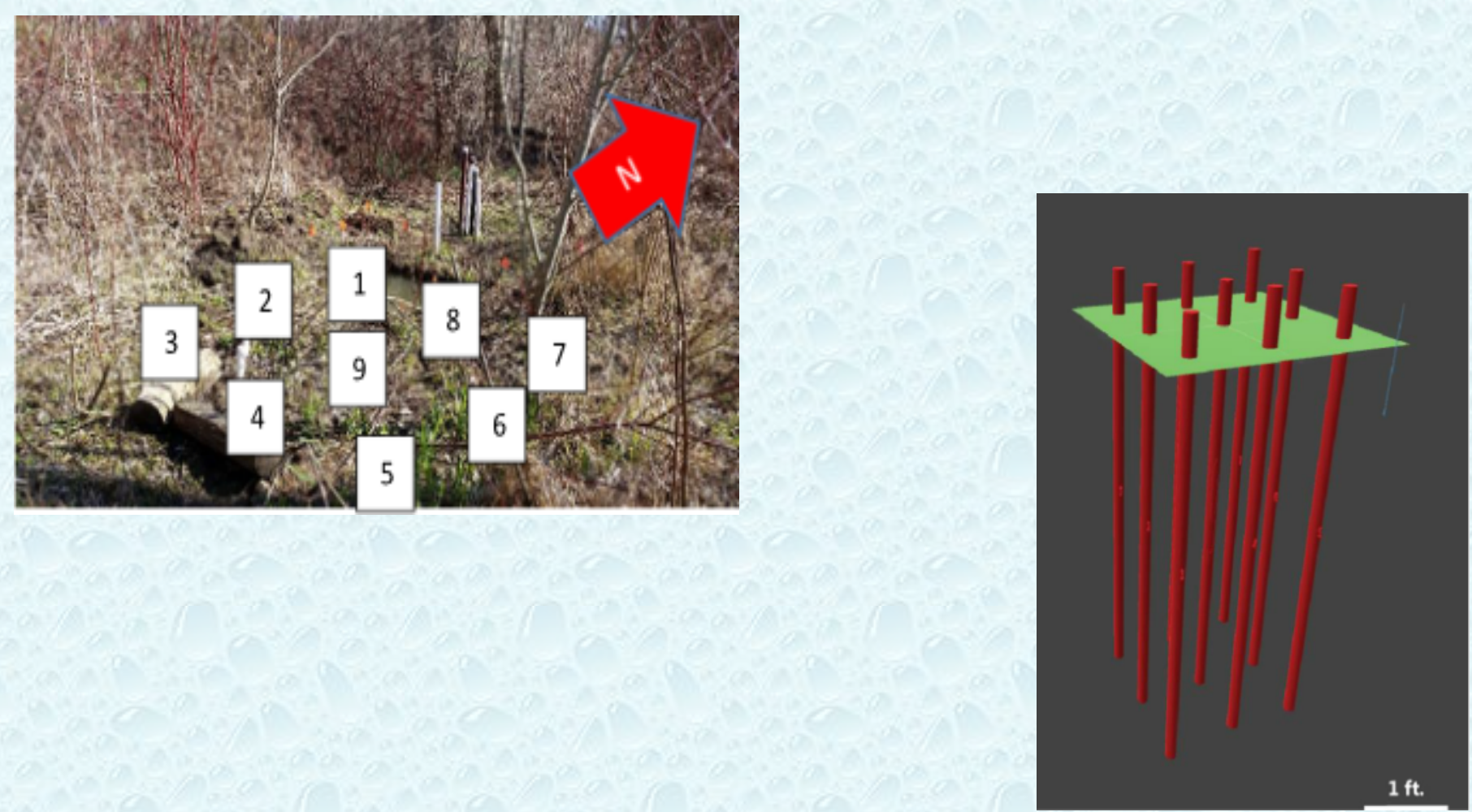
- 2007

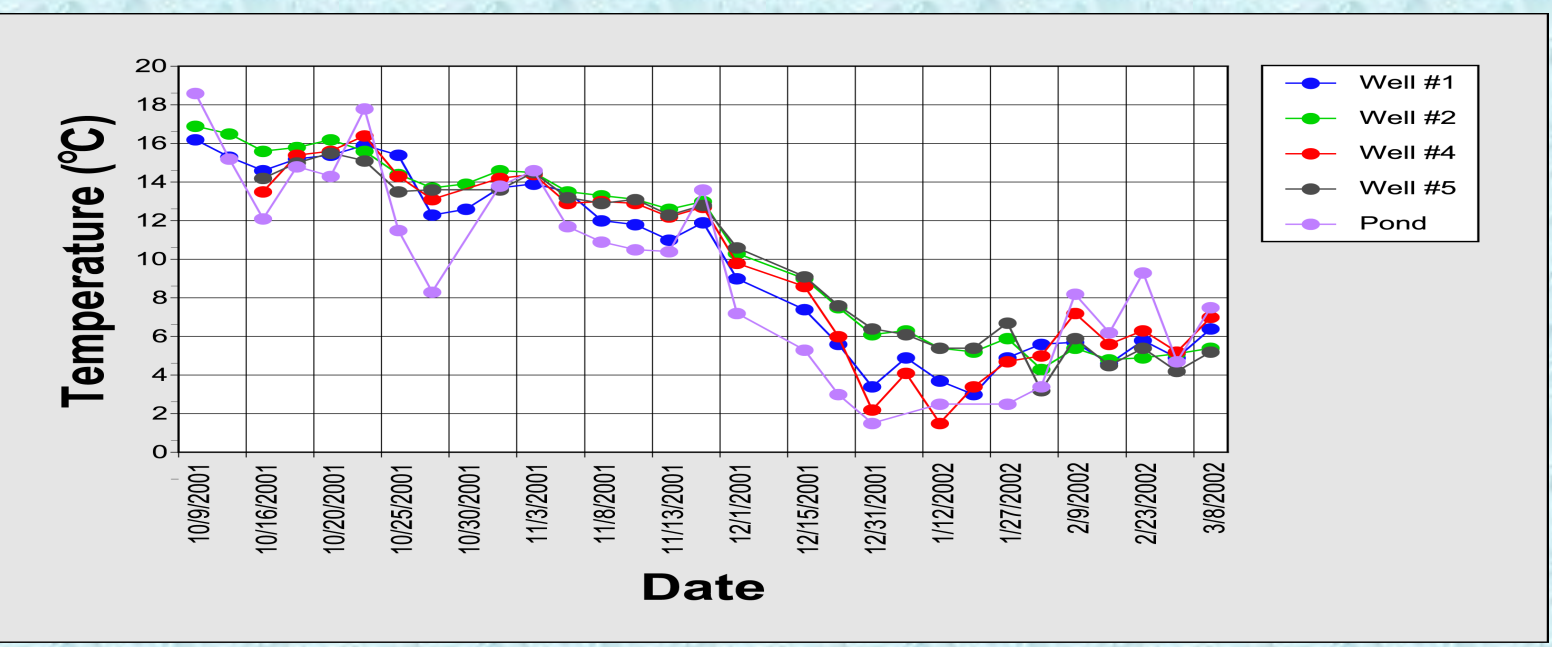




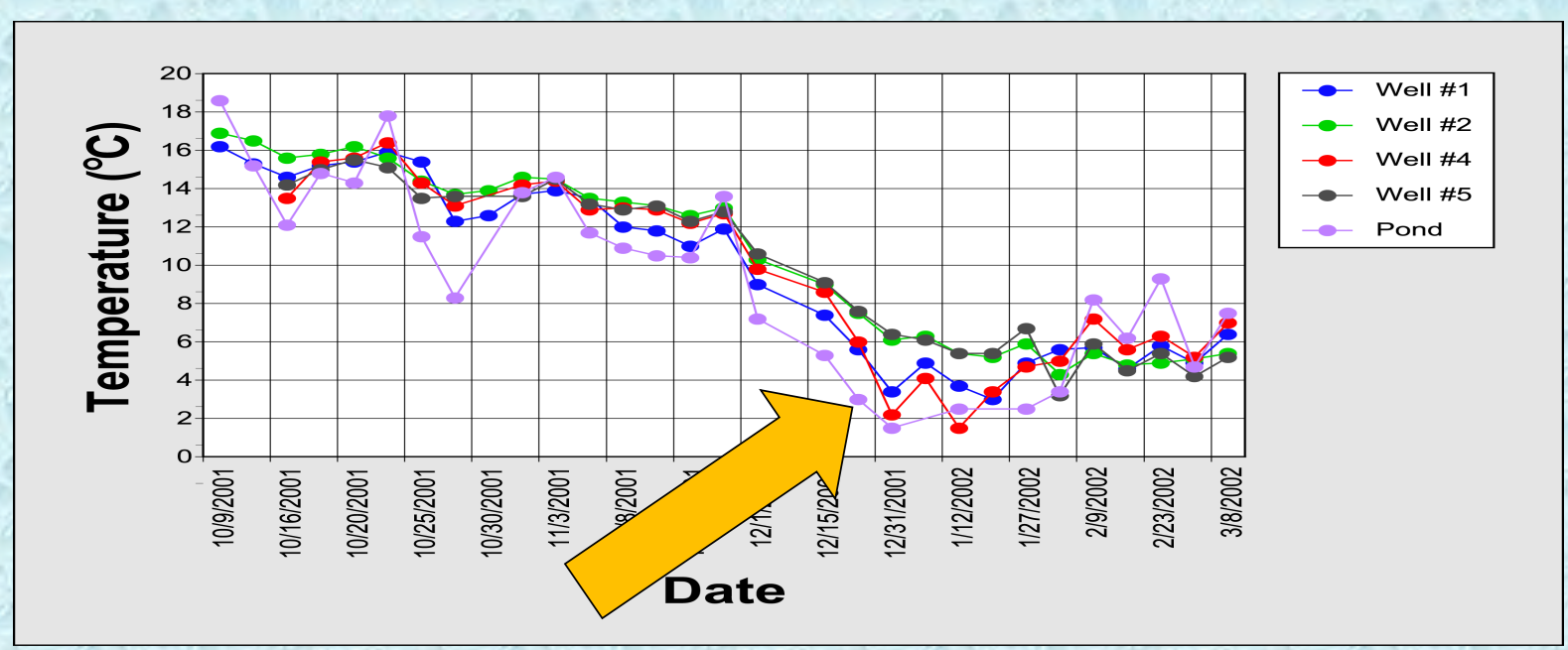

- *Isiorho, S. A. and *Daughdrill, G F., 2007. Student observes the effect of construction on water levels in a nearby Creek. Published in GSA Abstracts with Programs Vol. 39, No. 3, p. 21 


\section{Temperature trend}

Temp. (oC) trend Five Wells

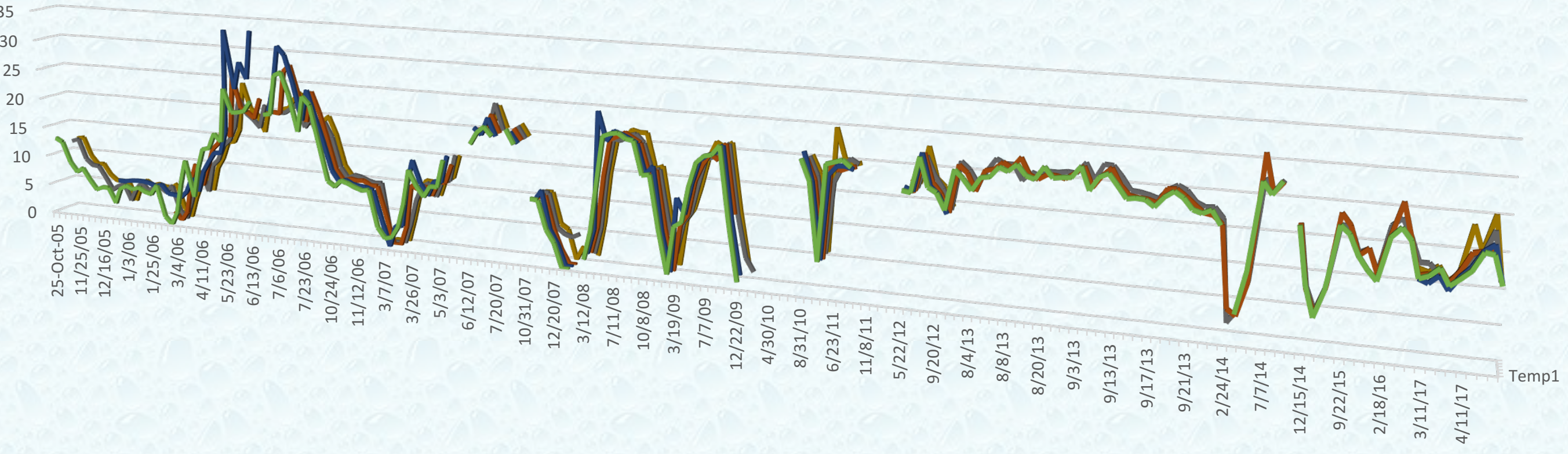




\section{Data:}

- 2016

More than a Decade Temperature Data

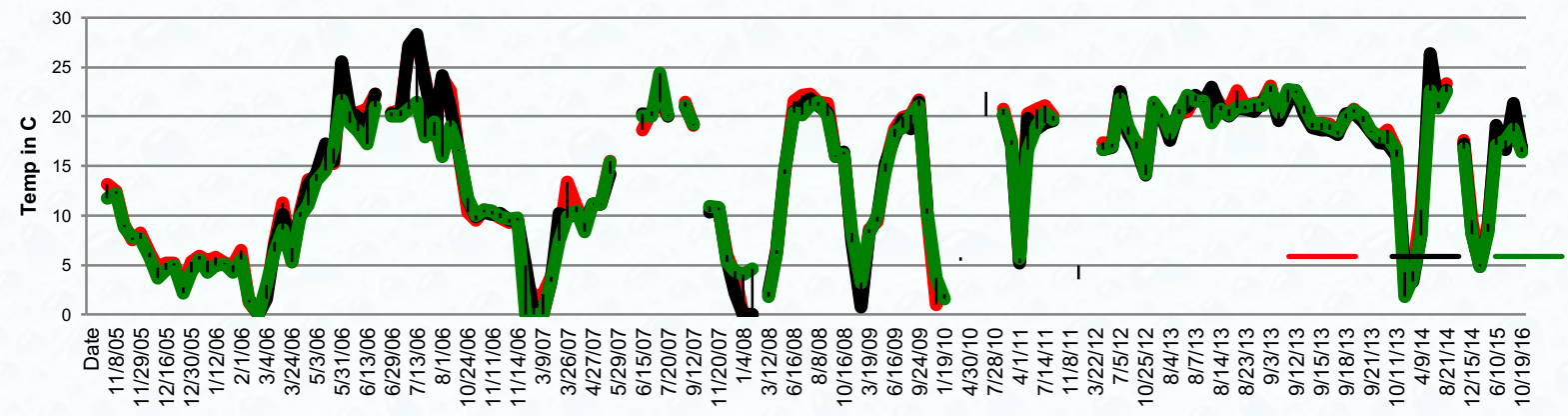

Date: Nov 2005 through Oct 2016

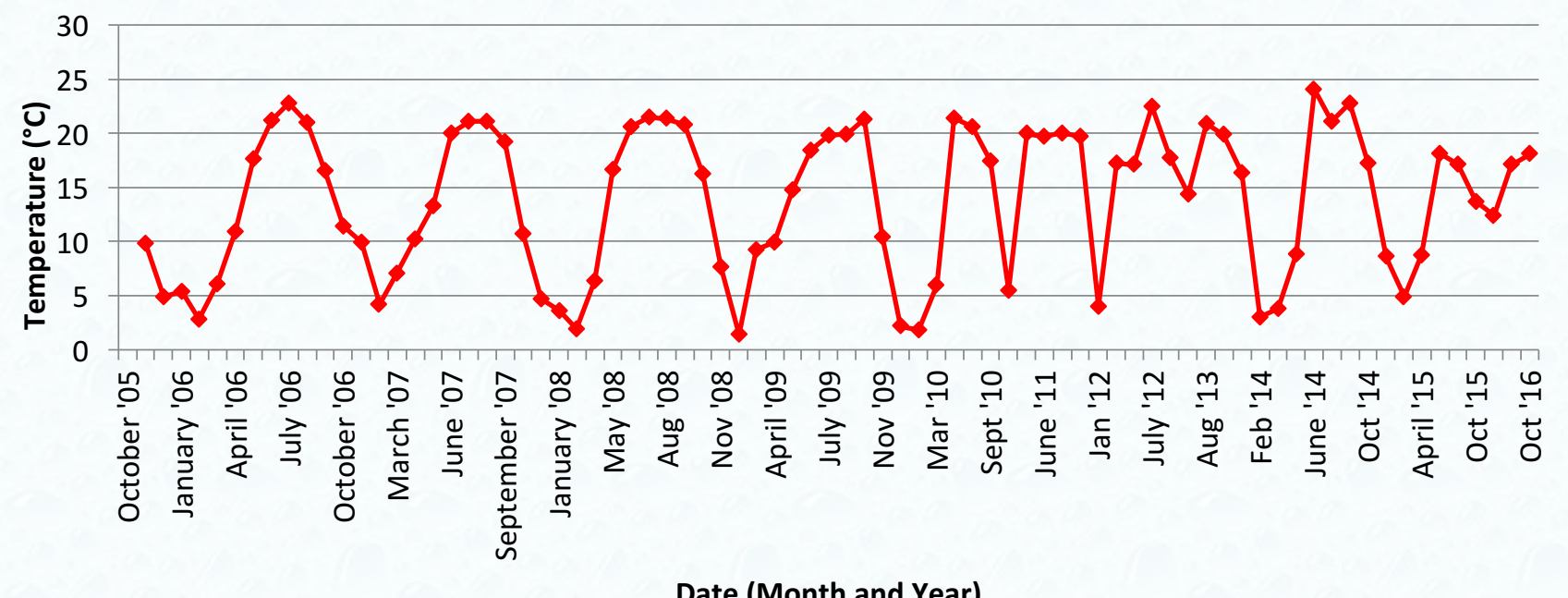

Date (Month and Year) 
Depth to Groundwater (2005-2017)
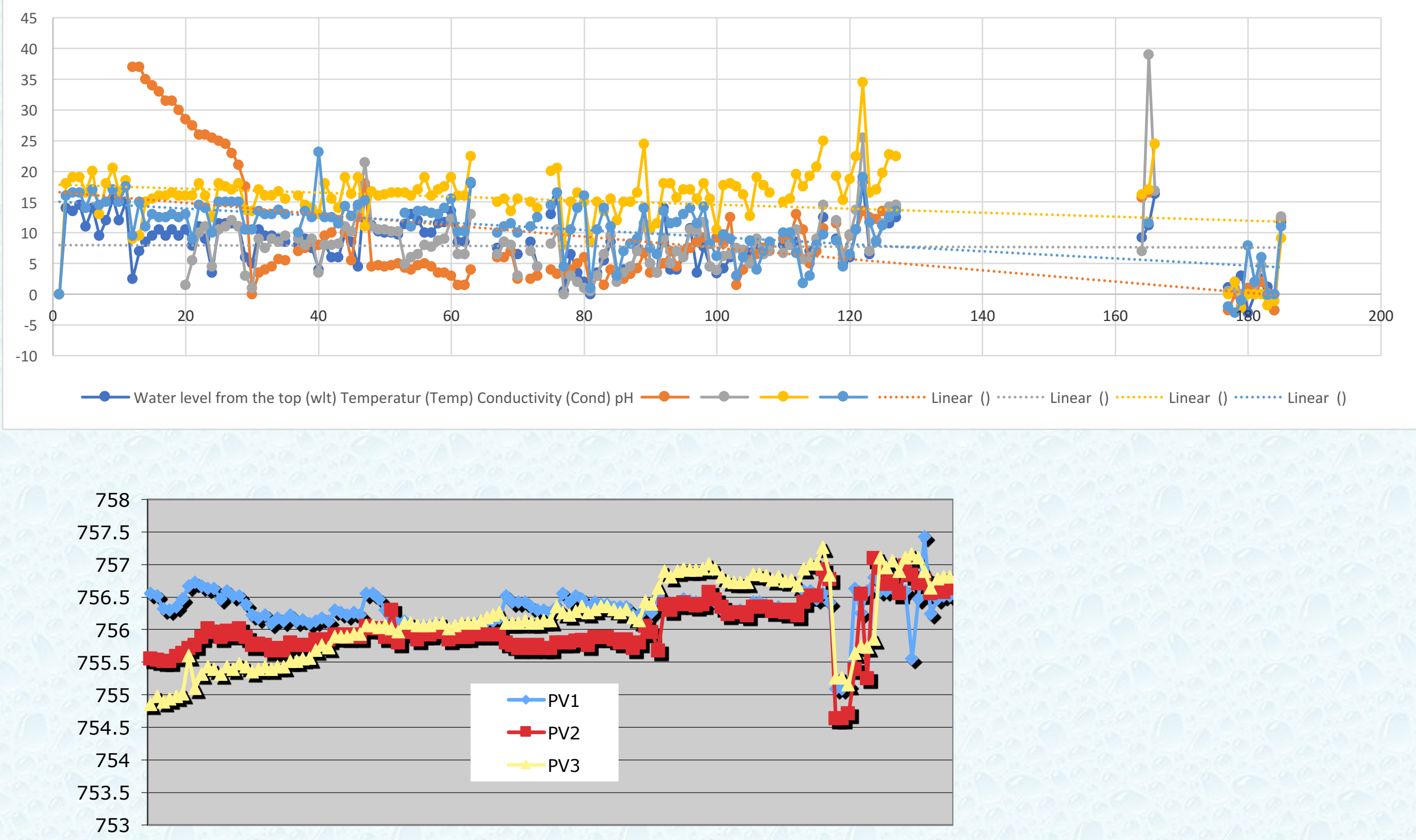


\section{Publications}

- More than 30 students' presentations at professional meetings.

- One examined the water quality across a mid-size Midwest city in USA

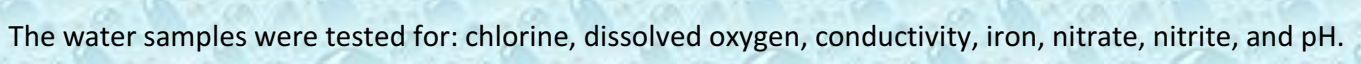

- Most students used data from the well field. 
- *Budd Sarah, K., Lafaucial, *Tammy, and Isiorho S. A., 2013, So you measured chemical parameters in a well field and now so what? GSA with programs. Vol. 45 , No. 7, p. 585

"Depth of well is inversely related to both temperature and concentration of Nitrates. It is directly related to the $\mathrm{pH}$ Conductivity is directly related to temperature and inversely related to Nitrates Temperature is directly related to Nitrates Wells 1 \& The river chemistry varied the most while the 12 -foot well varied the least. This implies that the river water and the other shallow wells are greatly affected by what goes on at or close to the land surface.

\begin{tabular}{|c|c|c|c|c|c|}
\hline \multirow[t]{2}{*}{ Date } & e Well & epth & $O_{44}$ & $\mathrm{O}_{44}$ & $\mathrm{NO}_{3}$ \\
\hline & 1 & 38.74 & 64 & 0.52 & 4.7 \\
\hline \multirow{4}{*}{$\stackrel{\infty}{\infty}_{\infty}^{m}$} & 3 & 30.48 & 97 & 0.47 & 6.4 \\
\hline & 5 & 45.40 & 10 & 1.68 & 11.5 \\
\hline & 12 & 0.00 & 117 & 0.02 & 0.0 \\
\hline & River & 20.32 & 69 & 0.27 & 3.0 \\
\hline \multirow{5}{*}{ 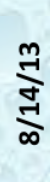 } & 1 & 29.53 & 79 & 4.71 & 0.0 \\
\hline & 3 & 24.45 & 102 & 2.21 & 0.0 \\
\hline & [ & 30.48 & 7 & 4.99 & 0.0 \\
\hline & 12 & 2.86 & 93 & 0.19 & 0.0 \\
\hline & River & 2.54 & 67 & 0.11 & 7.1 \\
\hline \multirow{5}{*}{$\underset{\infty}{\stackrel{m}{\infty}}$} & 1 & 46.67 & 82 & 7.86 & 0.0 \\
\hline & 3 & 47.31 & 85 & 5.06 & 0.0 \\
\hline & 5 & 47.31 & 3 & 6.35 & 0.0 \\
\hline & 12 & 21.91 & 191 & 0.29 & 0.0 \\
\hline & River & 36.83 & 101 & 0.38 & 2.1 \\
\hline
\end{tabular}




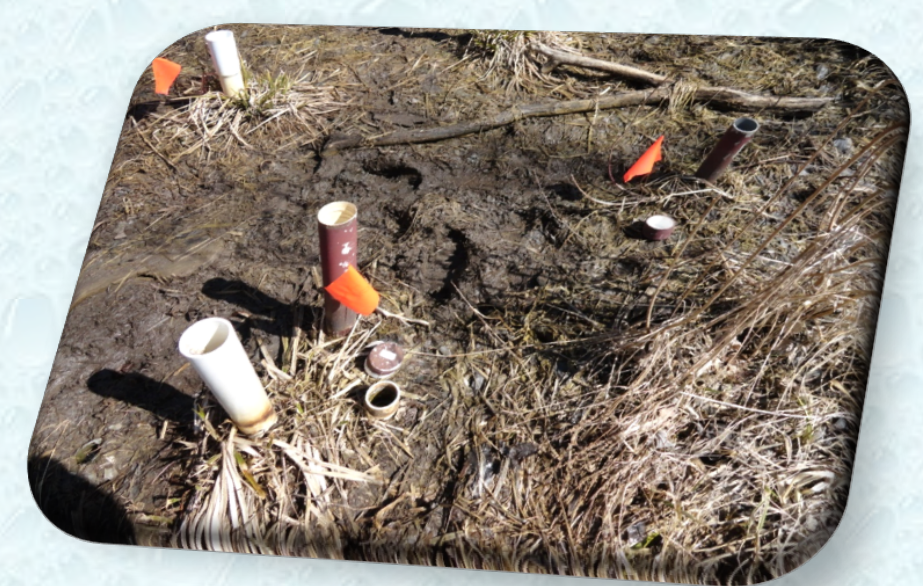

- *Matthews T., Budd Sarah, K., and Isiorho S. A., 2014, Determining the water quality at Indiana University-Purdue University' Fort Wayne (IPFW) using well data. In GS6 Abstracts with Programs. Vol. 45, No. 6, p. 531 water is fit to drink $\odot$

- *Yeaters Ross, and Isiorho S., 2016, Monitoring groundwater properties in a wetland on the IPFW campus. Indiana Academy of Science Abstract: 131st Annual Academy Meeting - Mar 26, 2016 - Mar 26, 2016. p 54 Hazen method for K-value of soil. Measure nitrite, nitrate, TDS, Temp, Cond, DO, elevation head.. +ve correlation btn head \& DO, GW flow direction is NE, nearby stream is an influent
stream

- *Cole, David, and Isiorho, Solomon, 2017, Monitoring changes in IPFW well field along St. Joe River. Poster presentation at the $20^{\text {th }}$ Annual Student

Research and Creative Symposium, IPFW, March 29, 2017 "The wetland is a recharge zone in the fall and a discharge zone in the Winter. The 12 foot well is believed to be an artesian aquifer. Conducting a sieve analysis could prove beneficial for soil
analysis. No immediate threat of flooding to the surrounding area"

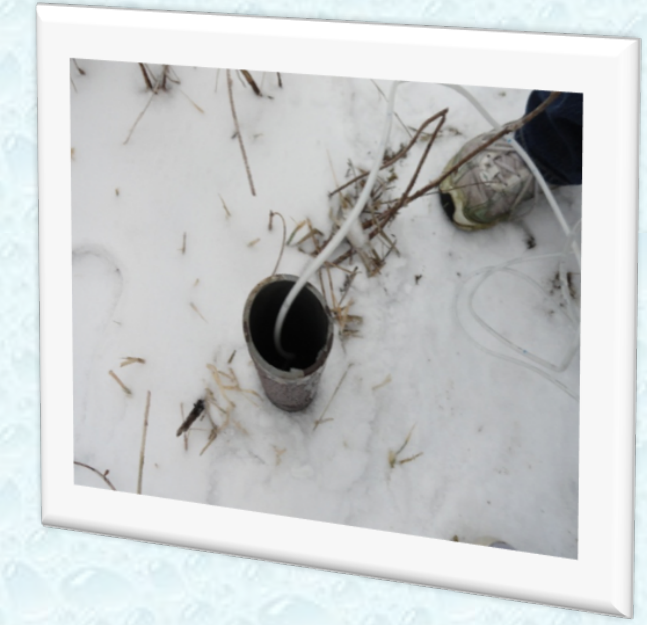




\section{Findings}

- The current data from 2004 through May of 2017 shows

- increase in groundwater temperature within the well field,

- rise in water levels, \&

- water becomes slightly acidic with time.

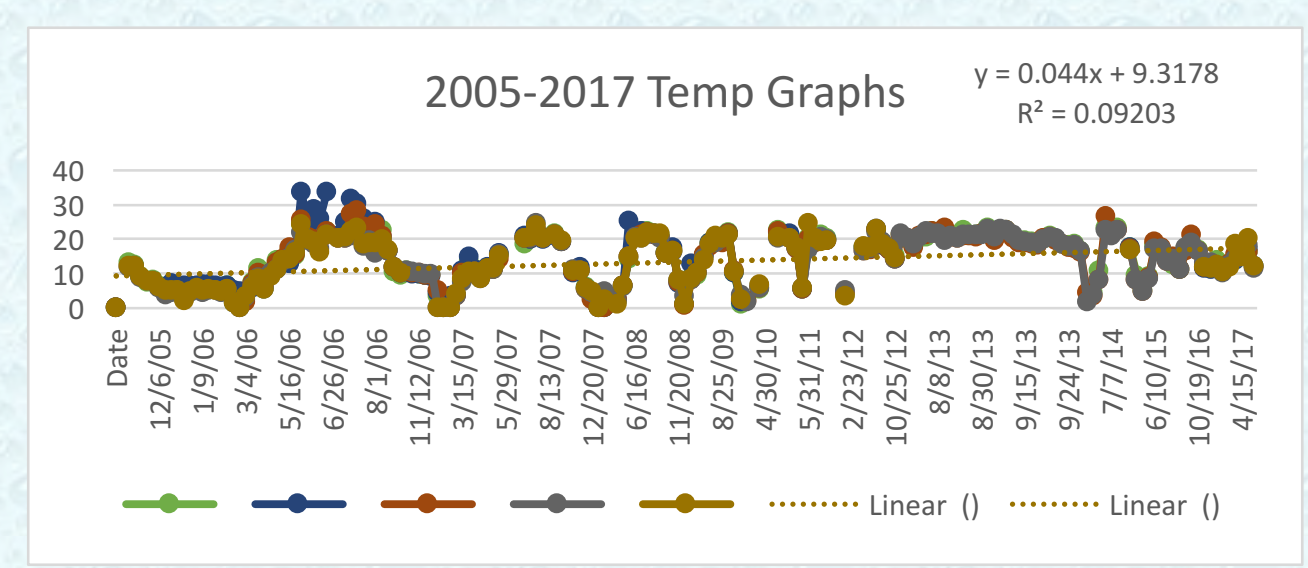

Chart Title

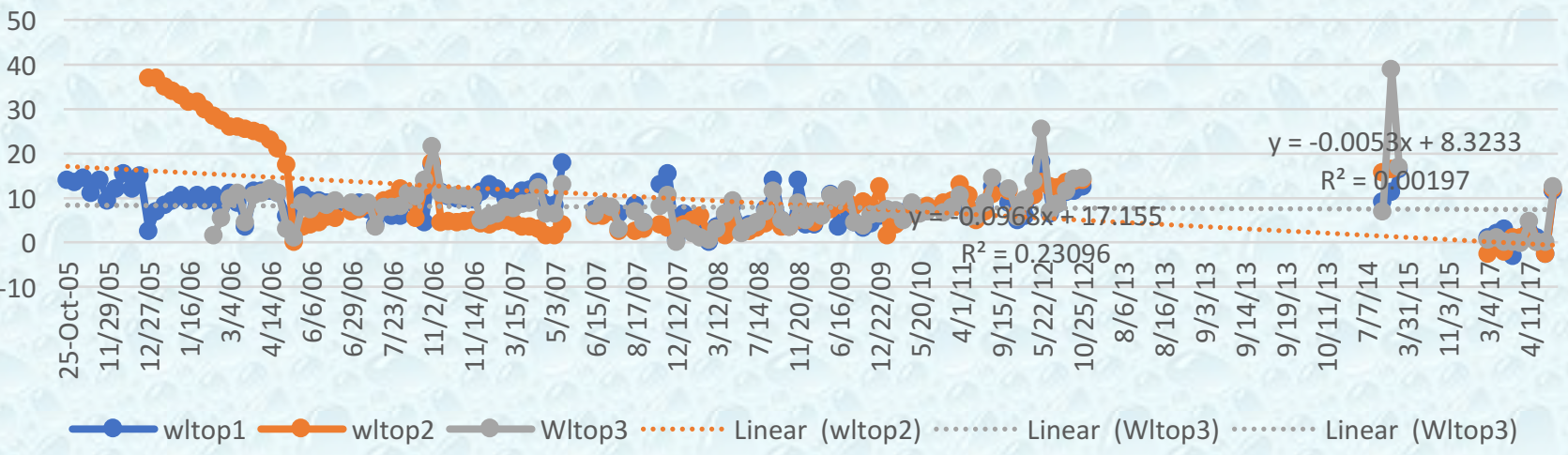

pH of Well Field

든

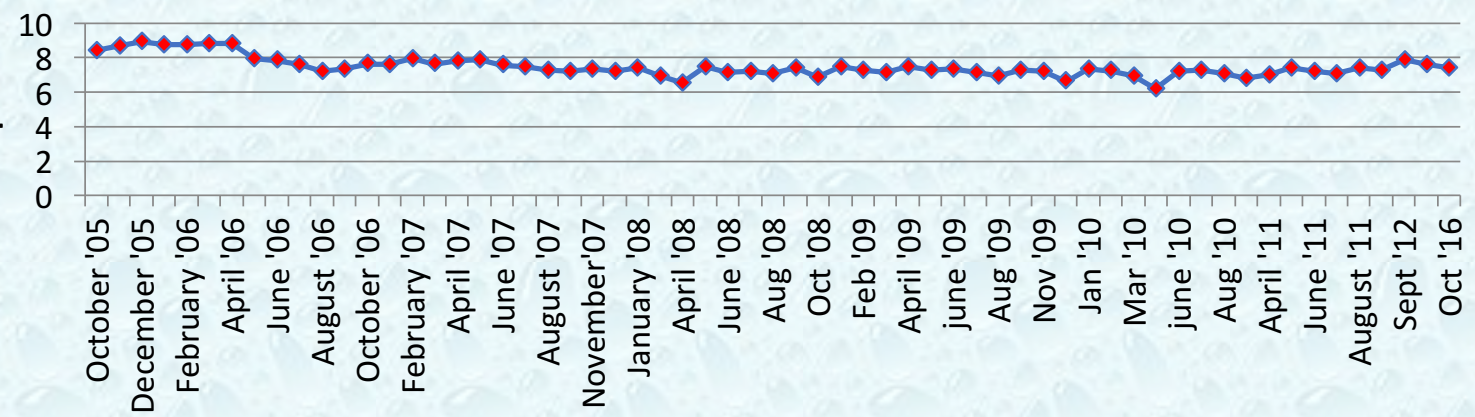




\section{Conclusions:}

Well field served as a convenient outdoor lab

Got students involved \&

Students learned about their water source

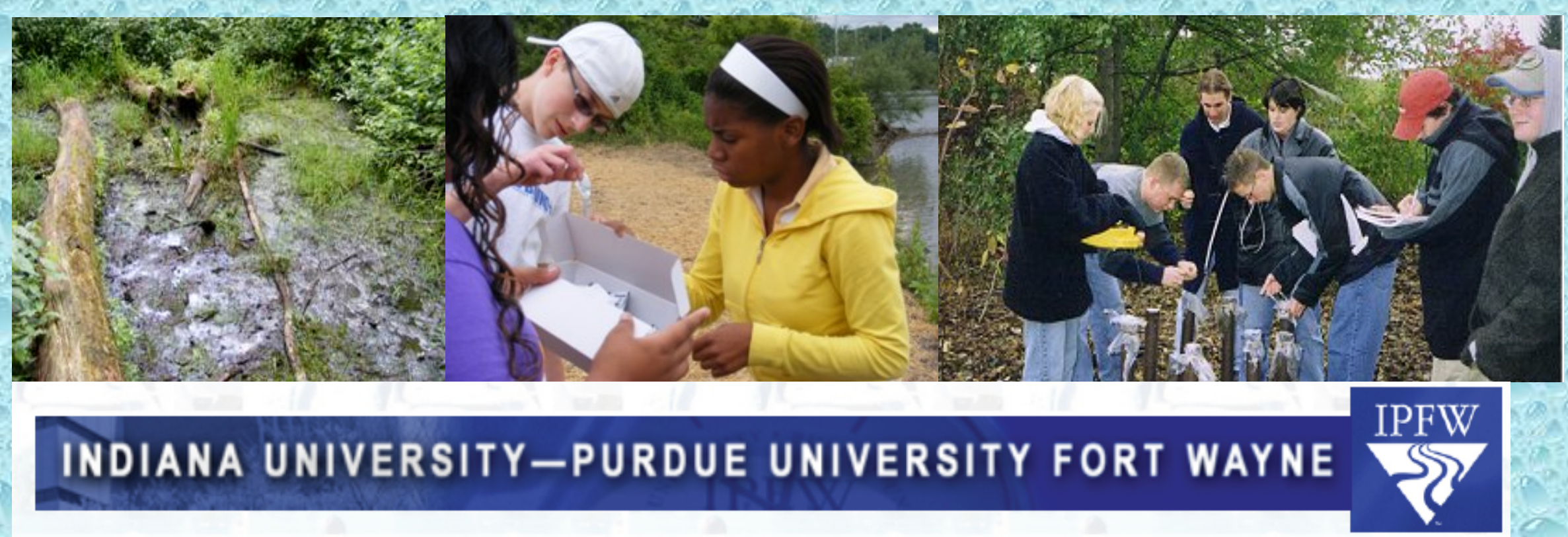

